\title{
The Leadership Management in improving the character
}

\section{SAFRI USMAN}

\begin{abstract}
The role of a leader in an organization is very important because the existence of the leader is to become a doorstop or become one of the spearheads of success in organization. The role of a leader is inseparable from the implementation of management functions in the organization, starting from the planning organization including budgeting, organizing, staffing, actuating or leadership, coordinating and controlling or evaluating. However, every operational journey an organization will encounter obstacles or problems due to the dynamics of the organization's internal and external environment. To get around these situations and conditions, we need the art of intelligent leadership to achieve leadership effectiveness.
\end{abstract}

\section{Introduction}

\section{A. Background}

Humans are social beings who cannot live alone, in human life they always interact with others and their environment. In order to create a harmonious organization, humans must have groups in a particular organization. Leadership is an organizational locomotive that is always interesting to talk about. This attractiveness is based on a historical background which shows the importance of the existence of a leader in every group activity, and the fact that a leader in every group activity is the center in the pattern of interaction between organizational components.

In an organization, it always involves several people who interact with each other intensively. These interactions are arranged in a structure that can help in achieving common goals. In order for the implementation of work in the organization to run properly, resources such as equipment, work methods, raw materials, and others are needed.

The role of a leader in an organization is very important because the existence of the leader is to become a doorstop or become one of the spearheads of success in organization. The role of a leader is inseparable from the implementation of management functions in the organization, starting from the planning organization including budgeting, organizing, staffing, actuating or leadership, coordinating and controlling or evaluating. However, every operational journey an organization will encounter obstacles or problems due to the dynamics of the organization's internal and external environment. To get around these situations and conditions, we need the art of intelligent leadership to achieve leadership effectiveness. 
One of the duties or roles of the leader is that he must be able to manage conflicts in the organization he leads so that each conflict can be resolved properly and no one feels disadvantaged. A leader is someone who works through other people by coordinating their activities in order to achieve organizational goals.

\section{B. Formulation of the problem}

The formulation of the problem is:

1. What is the meaning of leadership?

2. What is the definition of organization?

3. What are the different types of leadership roles?

4. What is the role of the leader in an organization?

5. What are some examples of the role of a leader in an organization?

\section{Purpose}

\section{General purpose}

Students are able to know about the role of leadership in organizations.

2. Specific goals

a. Know the meaning of leadership

b. Know the definition of organization.

c. Know the different kinds of leadership roles.

d. Knowing the role of a leader in an organization.

e. Knowing examples of the role of leaders in an organization

\section{Discussion}

\section{A. Definition of Leadership}

Many experts from management who gave their opinion about the definition of leadership where leadership is defined as the process of directing and influencing employees in activities related to the duties of group members. When we talk about leadership, it will not be separated from who is leading, which is called the leader. A leader is an individual who can apply the principles of motivation, discipline, and productivity, if he works with people, tasks and situations in order to achieve the goals of an effective leadership company, it depends on a solid managerial foundation. There are several definitions of leadership according to experts, including:

1. According to Howard H. Hyot quoted by Kartini Kartono in his book Leadership and Leadership (2004: 57) that "leadership is an art to influence human behavior, the ability to guide people".

2. Dubrin $(2005 ; 3)$ in his book leadership states that "leadership is an effort to influence many people through communication to achieve goals, how to influence people with directions or orders, actions that cause others to act or respond and cause positive change, dynamic power. important that motivates and 
coordinates the organization in order to achieve goals, the ability to create confidence and support among so that organizational goals can be achieved.

3. Siagian $(2002 ; 62)$ in his book human resource management argues that leadership is a person's ability to influence others (his subordinates), in such a way that other people want to do the will of the leader even though personally it may not be liked by him.

4. Nimran (2002: 62) that "leadership or leadership is a process of influencing the behavior of others to behave as desired".

Based on some of the definitions above, leadership is the process of influencing or setting an example by the leader to his followers in an effort to achieve organizational goals.

\section{B. Definition of Organization}

Organization comes from the word oranon, which in Greek means tool. The definition of organization has been conveyed by many experts, but basically there are no significant differences and as a comparison, several opinions will be conveyed as follows:

1. Chester 1. Barnard (1938), suggests that an organization is a system of cooperation between two or more people.

2. Jamnes D. Mooney, organization is every form of cooperation to achieve common goals.

3. Dimock, organization is a systematic combination of interdependent or related parts to form a unified whole through authority, coordination and supervision in an effort to achieve predetermined goals.

So an organization is a group of people (two or more) who are formally united in a collaboration to achieve predetermined goals.

\section{Definition of the Role of Leadership}

Before discussing the various kinds of leadership roles, we will first describe the understanding of the leadership role itself. Leadership is the process of influencing the activities of a group organized towards achieving goals. In another sense, leadership is the ability and skills of a person who occupies a position as head of a work unit to influence others, especially their subordinates, to think and act in such a way that through positive behavior he makes a real contribution to the achievement of organizational goals. While the definition of management is a process of planning, organizing,

In management, leadership is a sub system rather than management. Because considering the vital role of a leader in mobilizing subordinates, there is an idea among experts to be able to reveal much more about the roles that are the burden and responsibility of the leader in influencing his subordinates. There are several definitions of the role of leadership according to experts, including:

1. Sarbin and Allen (Thoha, 1995), formulated "the role as a series of regular behavior, which is caused by a certain position or because of something that is easily recognized".

2. Wahjosumidjo (1994), "the role of leadership is emphasized on a series of tasks that need to be done by each leader in relation to subordinates". 
3. Stoner and Mintzberg, both see leadership as a sub system of management.

4. Miftah Thoha (1995), argues that "in essence leadership has a rather broad understanding than management".

The definition of role itself is regulated and expected behavior of a person in a certain position. So the leadership role is a set of behaviors that are expected to be carried out by someone according to their position as a leader.

D. Various Leadership Roles

1. The Role of Leadership in Decision Making

The leadership of a person in an organization plays a very large role in every decision making, so making decisions and taking responsibility for the results is one of the leader's duties. So that if a leader is unable to make decisions, he should not be a leader.

On the other hand, decision making in the review of behavior reflects the character of a leader. Therefore, to find out whether a decision is good or not is not only judged by the consequences it causes, but through various considerations in the process. Decision-making activities are a form of leadership, so that:

a. Decision theory is a methodology for structuring and analyzing uncertain or risky situations, in this context decisions are more perspective than descriptive.

b. Decision making is a mental process in which a manager obtains and uses data by asking other questions, shifting answers to find relevant information and analyzing data; managers, individually and in teams, organize and supervise information especially their business information

c. Decision making is the process of choosing among alternative actions to solve a problem.

In its implementation, decision making can be seen from several aspects, namely:

a. Decision making process

The process is carried out in several stages such as:

1) Identify the problem

2) Defining the problem

3) Formulating and developing alternatives

4) Implementation of decisions

5) Evaluation of decisions

b. Decision making style

Apart from the decision-making process, there are also decision-making styles. Style is the lear habit or habit that is learned. The decision-making style is a quadrant bounded by dimensions:

1) Way of thinking, consisting of:

a) Logical and rational; process information serially

b) Intuitive and creative; understand something as a whole.

2) Tolerance to ambiguity

a) A high need to structure information in a way that minimizes ambiguity 
b) Low need to structure information, so that it can process many thoughts at the same time.

The combination of the two dimensions above produces decision-making styles such as:

a. The directive is a tolerance for low ambiguity and seeks rationality. Efficient, make decisions quickly and are short-term oriented.

b. Analytic is a tolerance for high ambiguity and seeks rationality. Careful decision maker, able to adapt to new situations.

c. Conceptual is a high tolerance for ambiguity and is intuitive. Long-term oriented, often pressing creative solutions to problems.

d. Behavioral is a low tolerance for ambiguity and is intuitive. Trying to avoid conflict and seek acceptance.

Based on the description above, the following are efforts that need to be taken, such as:

a. Digest the problem

In line with the role of leadership, there is a difference between the issue of objectives and methods.

In these conditions the role of the leader is to take the initiative in relation to goals and directions rather than methods and means.

b. Alternatives identification

Ability to obtain as many relevant alternatives as possible.

c. Set priorities

Choosing among many alternatives is the essence of the decision-making activity.

d. Take a step

Decision making efforts do not stop at the level of choice, but continue at the implementation and evaluation steps to provide feedback.

2. The Role of Leadership in Team Building

Teams are working groups that are formed with the aim of succeeding the common goals of an organization or community group. The purpose of team building here is to build general guidelines in forming or building a team, namely:

a. Instill in common interests

b. Using ceremonies and rituals

c. Use symbols to develop identification with the work unit

d. Encourages and facilitates satisfying social interactions

e. Hold team building meetings

f. Use consultant services if necessary.

Leadership is defined as the process of providing direction and influence on activities related to the tasks of a group of its members. They believe that the team will not be successful without combining the contributions of each member to achieve the same ultimate goal. The role of the leader in the team is as follows:

a. Show personal style 
b. Proactive in most relationships

c. Inspires teamwork

d. Provide mutual support

e. Get people engaged and engaged

f. Make it easy for others to see opportunities and achievements

g. Looking for people who want to excel and can work constructively

h. Encourage and make it easy for members to work

i. Recognizes the achievements of team members

j. Trying to maintain commitment

k. Place high value on teamwork.

3. The Role of Leaders in Human Resource Management

Why do customers often complain about the quality of products and services in a company. This is normal in line with the higher dynamics of preferences and customer criticality regarding quality. Therefore it takes the main role of management (a manager), namely carrying out management functions to obtain the results that are targeted by the company or desired by customers. Meanwhile, the role of a leader with quality leadership is to develop and improve the system so that the human resource quality development program is successful as expected. In practice, a manager in addition to carrying out management functions must also be able to carry out the quality leadership of human resources in a sustainable manner.

\section{The Vision Role}

A vision is a statement that relatively describes the aspirations or direction for the future of the organization. In other words, a vision statement must be able to attract attention but not cause misconceptions. With this leadership role, so that the vision is in line with future organizational goals, leaders must set and interpret goals for individuals and work units.

5. The Role of Leaders in Generating Enthusiasm

One of the leadership roles that must be played by a leader is the role of arousing morale. This role can be fulfilled by giving praise and support. Praise can be given in the form of rewards and incentives. Award is a form of praise that is not in the form of money, while incentives are praise in the form of money or objects that can be quantified. The provision of incentives should be based on mutually agreed and transparent rules. Incentives will be effective in increasing morale if they are given appropriately, meaning that they are in accordance with the level of needs of employees who are given incentives, delivered by the highest leadership in the organization, and given in a special "event".

The role of raising morale in the form of providing support can be done through words, either directly or indirectly, in suggestive sentences. Support can also be provided in the form of upgrading or adding work facilities, adding qualified staff, improving the work environment, and the like.

6. The Role of Leaders in Delivering Information 
Information is at the heart of the quality of a company or organization; This means that even though the company's products and after-sales service are good, if the internal and external communication is not good, then the company will not last long because the public will not recognize it and the work coordination in it is poor. The delivery or dissemination of information must be designed in such a way that the information actually reaches the intended communicant and provides the expected benefits. Information disseminated must be continuously monitored in order to know its internal and external impacts. Monitoring cannot be done carelessly, but it must really be designed effectively and systemically. Besides, A leader must also carry out a consulting role both within the organization and outside the organization properly, so as to create a good organizational culture. As a person who is at the top and is considered to have better knowledge than the one being led, a leader must also be able to provide appropriate and sympathetic guidance to his subordinates who have problems in carrying out their work.

\section{E. The Role of Leaders in the Organization}

Leadership in organizations includes all aspects. Leadership, of course, is very important for the running of the organization because if an organization runs without good leadership elements from its members as well as from the leadership of the organization, then any problems that arise in the running of the organization will be difficult to solve quickly and efficiently, which results in the goal of the organization. hampered. The characteristics of a successful leader are intelligent, conceptually skilled, creative, diplomatic, tactical, fluent in speaking, have knowledge of group assignments, and have social skills. There are several things that need to be considered so that leadership can play a good role, including:

1. The main basis for leadership effectiveness is not the appointment or appointment, but the acceptance of others for the leadership concerned

2. Leadership effectiveness is reflected in its ability to grow and develop

3. Leadership effectiveness requires the ability to "read" the situation

4. A person's behavior is not formed just like that, but through growth and development

5. A dynamic and harmonious organizational life can be created if each member is willing to adjust their way of thinking and acting to achieve organizational goals.

There are several leadership roles that must be present in an organization, namely:

1. Be fair (Arbitrating)

In the life of any organization, a sense of togetherness among its members is absolute. Because the sense of togetherness is essentially a reflection of the agreement between fellow subordinates, as well as between leaders and subordinates, in achieving organizational goals. But in certain cases there may be a discrepancy or problems in the relationship between subordinates. If they cannot solve the problem, the leader needs to step in to solve it immediately. In terms of solving relationship problems between subordinates, leaders must be unfair and impartial. 
2. Provide suggestions (suggesting)

Suggestions can be called suggestions or suggestions. In the context of leadership, suggestion is authority or influence that should be able to move the hearts of others. Suggestions have a very important role in maintaining and fostering a sense of devotion, participation and self-respect, as well as a sense of togetherness among subordinates.

3. Supporting the achievement of goals (supplying objectives)

The achievement of organizational goals does not happen automatically, but must be supported by various sources. Therefore, in order for any organization to be effective in terms of achieving its stated goals, as well as optimal utilization of its human resources, it is necessary to prepare adequate supporting sources. Such as mechanisms and work procedures, facilities, and other sources.

4. Catalyst (catalysing)

Chemically, the meaning of the word "catalyst" or catalyst is when it does not react, but speeds up the (chemical) reaction. In the world of leadership, a leader is said to play a role as a catalyst if the leader plays a role in always increasing the use of all existing human resources, trying to provide feedback that gives the spirit and work power as fast and as possible, and always appears as a pioneer and a carrier of change.

5. Creating a sense of security (providing security)

Every leader is obliged to create a sense of security for his subordinates. This function can only be carried out if each leader is always able to maintain positive things, an attitude of optimism in facing every problem, so that in carrying out his duties, subordinates feel safe, free from all feelings of anxiety, worry, and feel that they are guaranteed security. from the leadership.

6. As representatives of the organization (representing)

Every subordinate who works in any organizational unit always views his superior or leader as having a role in all areas of activity, especially leadership who adhere to the principle of "exemplary or role model". A leader is everything, therefore all his behavior, actions and words will always give a certain impression to the organization. The appearance and positive impressions of a leader will also provide a positive picture of the organization he leads. Thus every leader is none other than recognized as a figure who represents everything from the organization he leads.

7.Source of inspiration (inspiring)

A leader is essentially a source of enthusiasm for his subordinates. Therefore, every leader must always be able to arouse the enthusiasm of his subordinates, so that the subordinates accept and understand the organizational goals enthusiastically and work effectively towards the achievement of organizational goals.

8. Be respectful (praising)

Basically, everyone desires recognition and appreciation from others. Likewise, every subordinate in an organization needs recognition in the appreciation of his superior. Therefore, it is the duty of the leader to be willing to give appreciation or recognition in any form to his subordinates. 


\section{F. Leadership Role Case Examples}

"Examples of cases of leadership roles in crises of Nissan companies".

Competition always results in a winning party with a losing party. Companies that are able to achieve a competitive advantage will be the ones that come out as winners. What about companies that are unable to compete? There are only two choices, namely to fall out of business competition or change, as the famous phrase "Dead or Change!" Herein lies the important role of a leader. Where do you want the company to be taken to? The direction of the ship's destination depends on the captain of the ship, as well as the direction and strategy of the company which is very dependent on the leadership role to achieve its goals.

The leadership role in the company's crisis conditions can be seen from Nissan's persistence in moving out of the brink of failure. In 1998, the signs of the downfall of the Japanese auto giant were increasingly clear. Nissan officials were powerless to face business competition at that time, plus the accumulated debt of around tens of billions of US Dollars. During such an emergency, the goddess Fortuna still sided with Nissan. The French automotive company, Renault, has agreed to buy a 37 percent stake in Nissan on one condition, namely placing one of its envoys as CEO at Nissan. It was Carlos Ghosn, the figure behind the Nissan revolution to hit the global market again.

Upon arrival in Japan, Ghosn immediately determined a key step consisting of three steps. Ghosn's first step was to build confidence to change in every worker in the emergency. Reports point to the fact that Nissan has really been on the cusp of failure. There was no other way for Nissan but to get up to change. Changes made must be based on a vision for the future to penetrate the future global market, as well as a firm implementation of the company strategies that have been formulated.

The second step, Ghosn formulated two strategies in a plan which he called the Nissan Recovery Plan. The first strategy is to immediately revitalize Nissan's new products. The process of developing new products must be accelerated. To carry out this strategy, Nissan recruited Shiro Nakamura, a well-known car designer in Japan. On the other hand, the second strategy is to carry out cost efficiency as much as possible. Closing operational factories that are deemed less urgent, and shifting operations to focus more on central operations.

Ghosn's third step in perfecting his strategic stages was to form a core team that was directly led by him. The core team's task is very clear and decisive, namely to ensure that the Recovery Plan can be implemented optimally. No matter how perfect the plan is, it must be accompanied by a firm implementation. Here lies Ghosn's vital role in re-elevating Nissan's greatness in the global automotive market.

Hard work on this near impossible mission paid off in 2001 and in the years that followed. The giant has risen to show achievement after achievement. In 2005, its flagship product, Nissan X-Trail, strolled into the prima donna of the global automotive market. Followed by the Nissan Grand Livina which also boomed in 2007. Behind the success of Nissan's success, was the role of Charles Ghosn who brought Nissan out of the brink of bankruptcy. Their leadership with full confidence in facing a crisis 
situation is able to encourage optimal performance of each employee to achieve Nissan's big vision with firm implementation. That is the role of Carlos Ghosn's leadership in this heroic drama to once again fly Nissan's glory on the global stage.

So the role of leadership is very vital in the company's strategy to face times of crisis, with a vision for the future as the direction of the company accompanied by a firm application to regain business excellence.

\section{Conclusion}

Based on the discussion of the problems previously described, it can be concluded in this closing section that a good leader is needed in an organization. Besides the leader, the future of the organization also depends on the hands of the members, only a leader who has good leadership can advance the organization. The leader is not a dictator, here the leader is just a tool to motivate other members to achieve certain goals. So the leader really plays a role in an organization or company. A good leader can be an example for his members.

\section{REFERENCES}

[1] Yapanto, LM, Harahab, N., \& Olii, AH (nd). The Coastal communities and alternative income In Bone Bolango Regency, Gorontalo Province of Indonesia.

[2] Winardi. 2000. Leadership in management. Second printing. Jakarta; PT. Remika

[3] Mappaenre, A. 2004. Leadership. FEIS-UNM Office Administration Study Program, Makassar

[4] Yapanto, LM, Musa, DT, Tanipu, F., \& Suherman, S. (nd). The Impact of Covid-19 on Supply Chain Fisheries and Challenges by Fisherman in Indonesia. 22 (10), 1360-1365.

[5] Mappaenre, A. 2009. Basics of Administration and Management Science, FEIS-UNM, Makassar

[6] Maxwell, john C., Developing the Leadership Within You (translation), Jakarta: Binarpura Aksara, 1995

[7] Judge. Timothy and Stephen P. Robbins. 2008. Organizational Behavior. Edition 12. Jakarta: Four Salemba.

[8] Herususilofia.lecture.ub.ac.id on "The Leadership Role of pdf” accessed on 23 April 2015

[9] Baruadi, ASR, Yapanto, LM, \& Akuba, AR (2020). The welfare of tuna fishermen in Gorontalo District; (Case study in the village of Kayubulan, Gorontalo). 29 (4), 5289-5297.

[10] Yapanto, LM, Tanipu, F., Paramata, AR, \& Actors, E. (2020). THE EFFECTIVENESS OF FISHERY COOPERATIVE INSTITUTIONS. 17 (25), 1329-1338.

[11] Setiawan, R., Pio, L., Cavaliere, L., Sankaran, D., Rani, K., Yapanto, LM,... Foggia, U. (nd). Access to Financial Services and Women Empowerment, through Microfinance eligibility. (1), 841-859. 
